\title{
A STUDY OF THE FORMATION OF THE SURAL NERVE IN ADULT MAN
}

\author{
DONALI) F. HUELKE \\ Department of Anatomy, University of Michigan Medical School, \\ Ann Arbor, Michigan \\ FIVE FIGURES \\ INTRODUCTION
}

According to textbooks of anatomy the sural nerve is either a direct continuation of the medial sural cutaneous branch of the tibial nerve or is formed by the union of this nerve with the peroneal communicating branch of the lateral sural cutaneous nerve (a branch of the common peroneal nerve). This union may take place anywhere between the popliteal fossa and the lateral malleolus.

Information on the site and type of formation of the sural nerve in various nationalities has been gathered by Bardeen ('06), Gluschkow ('18), Catania ('24), Kosinski ('25), Andreassi ('31), Ssokolow ('33), Mogi ('38), P'an ('39) and Williams ('54). In the majority of these studies the cadaver material was known to be of one nationality. In general, however, the nationality and the degree of racial mixture of the cadaver material in the United States is unknown to the anatomist.

\section{MATERIALS AND METHODS}

The material of this study consisted of 352 lower limbs of which approximately $70 \%$ were dissected by the author. The remainder were checked and recorded by the author from routine classroom dissections. One hundred eighty-one $(51.4 \%)$ right side and $171(48.6 \%)$ left side dissections 
were recorded. Separation according to race and sex was not made.

The data here presented were obtained by examination of material in the Anatomy Department of the University of Illinois School of Medicine; Loyola University School of Medicine; The Chicago Medical School; The University of Chicago School of Medicine; University of Michigan Medical School; and the University of Illinois, Department of Physiology, Urbana, Illinois.

To determine the cutaneous pattern of the posterior aspect of the leg, the tibial and common peroneal nerves were isolated in the popliteal fossa. Each nerve was then dissected to expose the origin of the medial sural cutaneous, the lateral sural cutaneous, and the peroneal communicating branches. These nerves were then traced to their termination. The manner in which the sural nerve was formed was recorded, and, if the pattern of the formation proved unusual, a sketch was made (figs. $2,3,4,5$ ).

\section{OBSERVATIONS AND RESULTS}

Three types of sural nerves, designated A, B, and C may be described (after P'an, '39). In type A, the sural nerve is formed by the union of the medial sural cutaneous branch of the tibial nerve and the peroneal communicating branch of the common peroneal nerve. Occasionally the peroneal communicating branch joins the medial sural cutaneous nerve by more than one branch (figs. 4 and 5). The union of these two nerves occurs in the lower half of the leg. In type B, the sural nerve is the continuation of the medial sural cutaneous nerve and the peroneal communicating branch is absent. The type $\mathrm{C}$ sural nerve is formed by the peroneal communicating branch only. This type is rare; in only one specimen was the medial sural cutaneous nerve completely absent (fig. 1).

The frequency of occurrence of the three types of sural nerves is presented in table 1 . Of the 352 lower extremities, 284 or $80.7 \%$ belong to type $A$; 67 limbs (19.0\%), to type B; 
and only one limb $(0.3 \%)$, to type $\mathrm{C}$. The $\mathrm{A}$ and $\mathrm{B}$ types appear with the same frequency whether in the right or the left limb.

Previous investigations of the formation of the sural nerve in American cadavers have shown conflicting results (table 2). The data of Williams agree closely with those of this study,

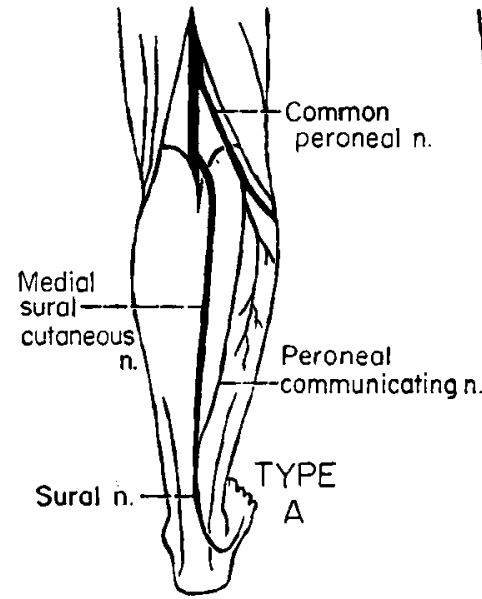

$80.7 \%$

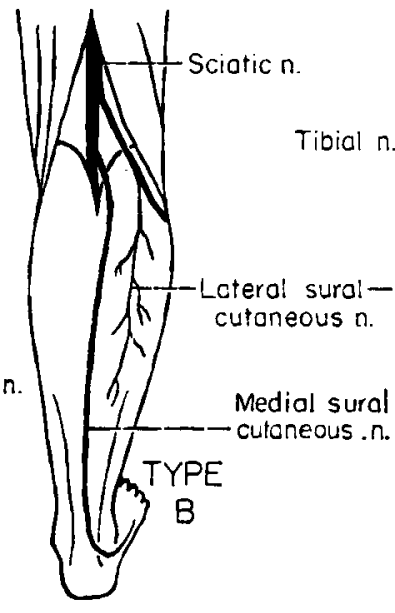

$19.0 \%$

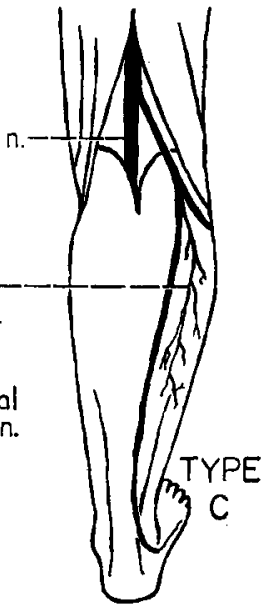

$0.3 \%$

Fig. 1 The manner of formation of the sural nerve. A type A sural nerve is formed by both components. A type $B$ nerve is a continuation of the medial sural cutaneous nerve. Type $C$ is the rare type of formation in which only the peroneal communicating branch extends to the foot as the sural nerve.

TABLE 1

The distribution of the three types of sural nerves

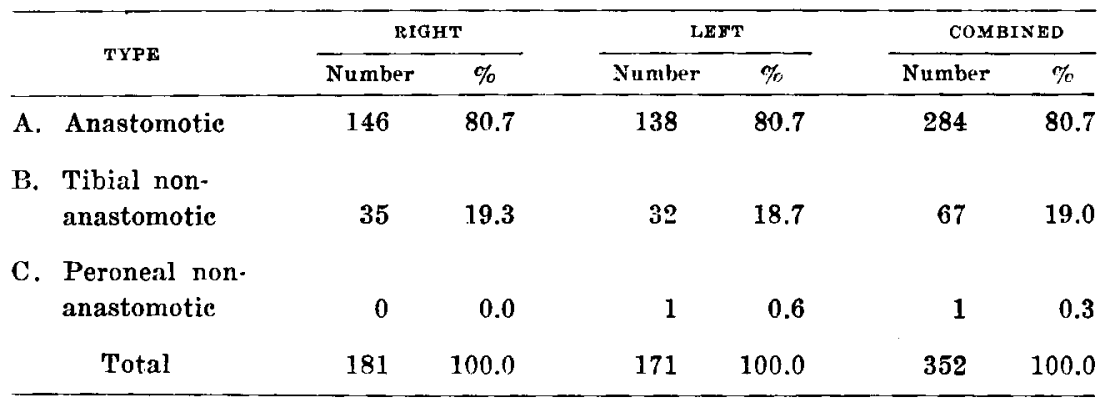


but Bardeen's data differ considerably. He indicated that the type A formation is found in only $59.2 \%$ of cases, while type $\mathrm{B}$ occurred in $39.5 \%$ of the dissections.

Examination of the distribution of the three types of sural nerves in Chinese, Japanese, Russian, Italian and Polish material show a marked difference between the Oriental and European groups (table 3). Comparison of tables 2 and 3 reveals that American and Oriental groups are quite similar both having approximately the same distribution of the three types of sural nerve. It might be expected that the present findings and those of Williams would approximate those of

TABLE 2

Frequency of the three types of sural nerves in American cadavers

\begin{tabular}{|c|c|c|c|}
\hline TYPES & $\begin{array}{c}\text { HUELKW } \\
1956 \\
352 \text { Cases }\end{array}$ & $\begin{array}{l}\text { WiLliaMs } \\
1954 \\
257 \text { Cases }\end{array}$ & $\begin{array}{c}\text { BARDEEN } \\
1906 \\
76 \text { Cases }\end{array}$ \\
\hline & $\%$ & $\%$ & $\%$ \\
\hline A. Anastomotic & 80.7 & 83.7 & 59.2 \\
\hline $\begin{array}{l}\text { B. Tibial non- } \\
\text { anastomotic }\end{array}$ & 19.0 & 15.9 & 39.5 \\
\hline $\begin{array}{l}\text { C. Peroneal non- } \\
\text { anastomotic }\end{array}$ & 0.3 & 0.4 & 1.3 \\
\hline
\end{tabular}

${ }^{1}$ In this study, data were taken from 132 limbs which were also used by Williams in his report.

the European series since most of the American cadavers are Caucasian $(89.8 \%$ in this study; Williams - 83.1\%). This is not the case however, for the European groups have a markedly different distribution of the three types of sural nerves (table 3 ). The non-Caucasian limbs of this study are from Negro cadavers. The findings on these limbs do not alter the percentages presented, for the type A sural nerve is predominant among the Negro cadavers.

In type $A$ the site of union of the medial sural cutaneous nerve and the peroneal communicating branch is extremely variable. This union may take place anywhere between the popliteal fossa and the lateral malleolus. In recording the 

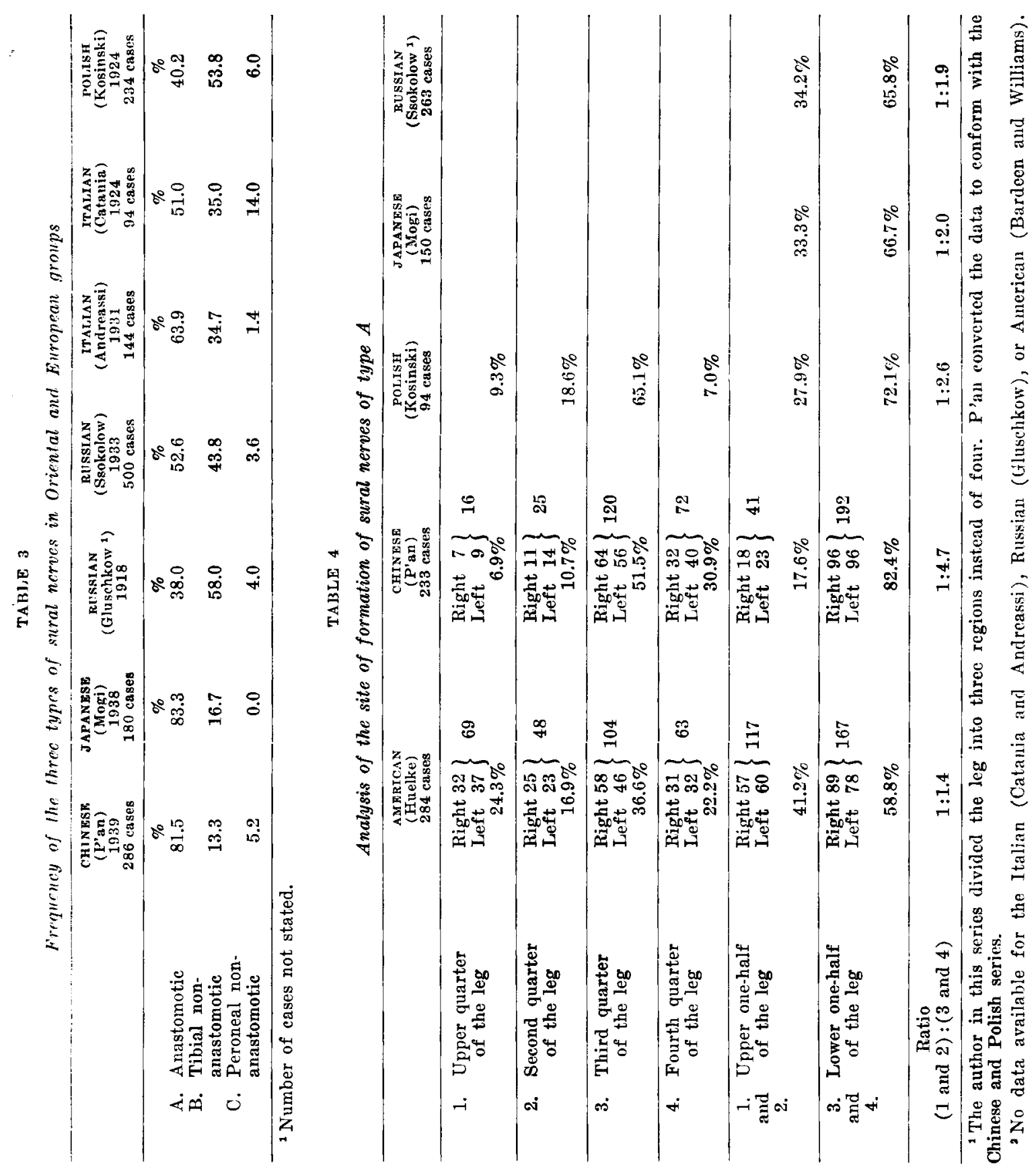


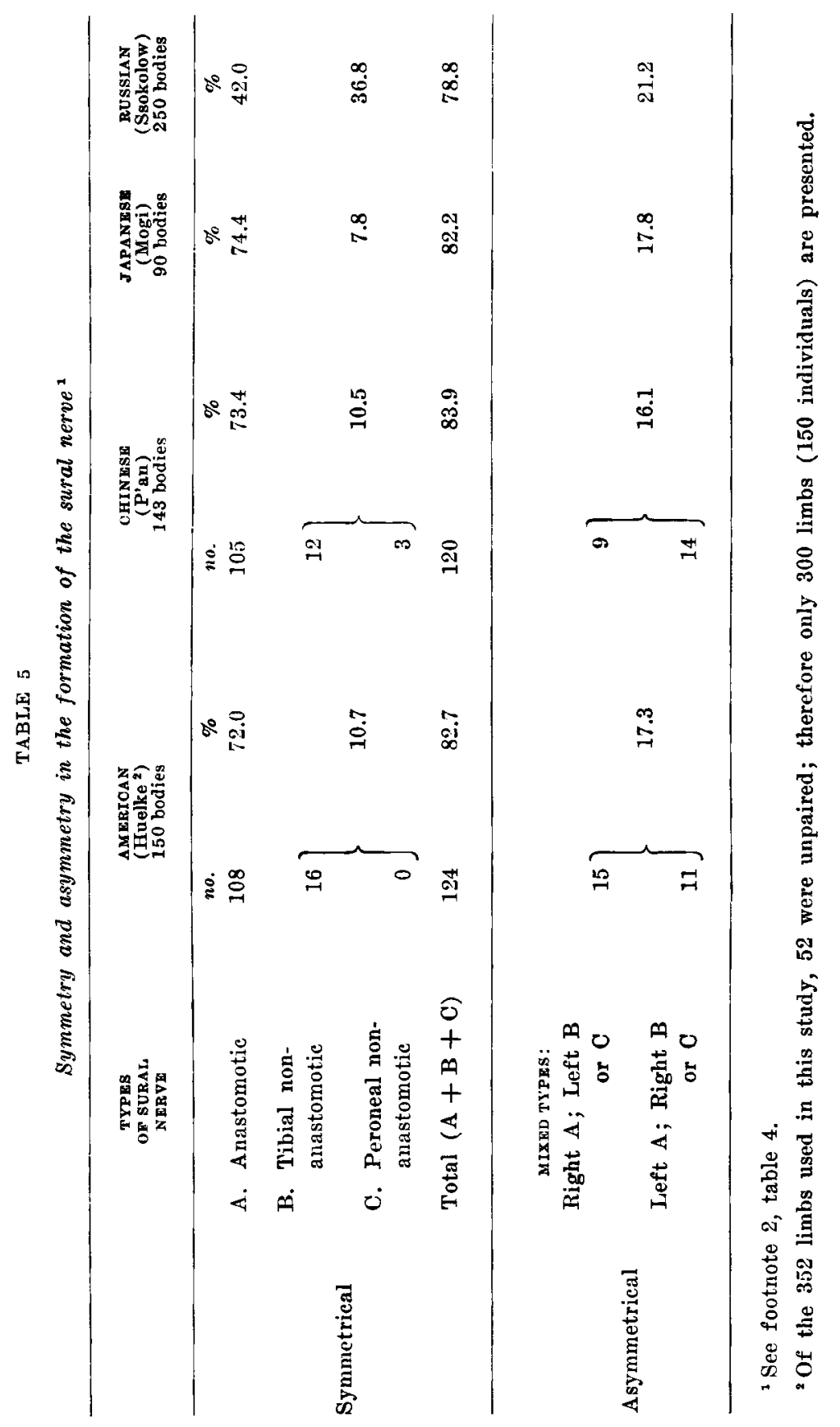


observations, each leg was considered to be divided into 4 parts. The popliteal fossa was designated as region 1 . The limb distal to the fossa was divided into three equal parts - the second quarter, the third quarter, and the fourth quarter of the leg. Analysis of the level of formation of the type A sural nerve of this study, along with the data collected by other investigators, is presented in table 4 .

The Chinese and Polish series are very much alike in that the sural nerve is formed more frequently in the lower half of the leg than in the upper, and most frequently in the third quarter of the leg. The Japanese and Russian series also show the lower half of the leg as being the more frequent site of union.

The data collected in this study indicate that the third quarter of the leg is the most constant site for the formation of the sural nerve. The ratio between the upper half and the lower half of the legs examined is $1: 1.4$, whereas in the nationalities mentioned above this ratio is more striking, Chinese 1:4.7; Polish 1:2.6; Japanese 1:2.0; Russian 1:1.9 (table 4).

Observations on symmetry and asymmetry in the formation of the sural nerve in both legs of the same body are presented in table 5. The symmetrical group had the same type of formation in both legs, while the asymmetrical group had the anastomotic type (A) in one leg and a non-anastomotic type ( $\mathrm{B}$ or $\mathrm{C}$ ) in the other leg.

In 150 bodies (300 paired lower limbs), 124 nerve patterns were symmetrical and 26 were asymmetrical. Of the 124 symmetrical patterns 108 were the anastomotic type (A); 16 were of the non-anastomotic type (B). The American, Chinese, Japanese and Russian groups had practically the same percentage of symmetrical and asymmetrical distribution. In the symmetrical group the anastomotic type was more frequent in the American (72.0\%), Chinese (73.4\%) and Japanese $(74.4 \%)$ than in the Russian $(42.0 \%)$. Conversely the non-anastomotic type appeared more often $(36.8 \%)$ in 
the Russian group than in the American (10.7\%), Chinese $(10.5 \%)$ or Japanese (7.8\%) groups.

Information on the distribution of the cutaneous nerves in anthropoids indicates that the sural nerve is always of the tibial non-anastomotic type (Ssokolow, '33). In man the formation of this nerve is more complex; in $80.7 \%$ the sural nerve is formed by two component branches, one from the tibial nerve, the other from the common peroneal nerve. Rarely $(0.3 \%)$ is it formed only by a branch from the common peroneal nerve. Approximately one instance in five is of the tibial non-anastomotic type, which is the constant type among the anthropoids.

\section{SUMMARY}

1. The site and formation of the sural nerve were studied in 352 lower limbs of adult cadavers from midwestern United States.

2. The sural nerve was formed by two components; one from the tibial, the other from the common peroneal nerve in 284 limbs $(80.7 \%)$. Occasionally the sural nerve is a continuation of the tibial portion only $(19.0 \%)$; very rarely does it consist of a peroneal branch without a tibial component $(0.3 \%)$.

3. The sural nerve was formed most frequently in the third quarter of the leg $(36.6 \%)$ and more often in the lower half $(58.8 \%)$ than in the upper half $(41.2 \%)$.

4. The majority of cadavers $(82.7 \%)$ had the same type of sural nerve in both legs.

5 . The similarities of the site and formation of the sural nerve in American, Chinese and Japanese bodies, and the differences between these and European groups are noted.

\section{ACKNOWLEDGMENT}

The author is indebted to Dr. W. P. Elhardt, Department of Physiology, University of Illinois; Drs. R. T. Woodburne, 
W. T. Dempster, and T. M. Oelrich, Department of Anatomy, University of Michigan Medical School, for their encourag'ement, assistance and criticism.

\section{LITERATURE CITED}

ANDREassi, G. 1931 Osservazioni intorno all'origine, comportamento e distribuzione dei nervi cutaneo mediale della sura, ramo anastomotico peoniero e cutaneo laterale della sura nell'uomo. Ricerche di Morfologia, 11 : 83-100.

BardeEN, C. R. 1906 Development and variation of the nerves and the musculature of the inferior extremity and of the neighboring regions of the trunk in man. Am. J. Anat., $6: 259-391$.

Catania, V. 1924 Il comportamento dei nervi cutanei dorsali del piede. Arch. ital. de anat. e di embriol., 21 : 295-331.

Gluschkow, P. A. 1918 Über die Innervation des Füssruckens. Kasan (Russia). Taken from Ssokolow, 1933.

Kosinski, C. 1926 The course, mutual relations and distribution of the cutaneous nerves of the metazonal region of the leg and foot. J. Anat., 60: $274-297$.

Moar, E. 1938 Über die Sensiblen Wandennerven bei den Japanischen Zwillingen. Okaj. Folia Anat. Jap., 16: 229-274.

P'AN, M. T. 1939 Formation of the sural nerve in the Chinese. Anl. J. Phys. Anthrop., 25: 311-321.

Ssokolow, P. 1933 Zur Anatomie des n. suralis beim Mensehen und Affen. Ztschr. f. d. ges. Anat., 100: 194-217.

Williams, D. D. 1954 A study of the human fibular communicating nerve. Anat. Rec., 120: 533-544. 


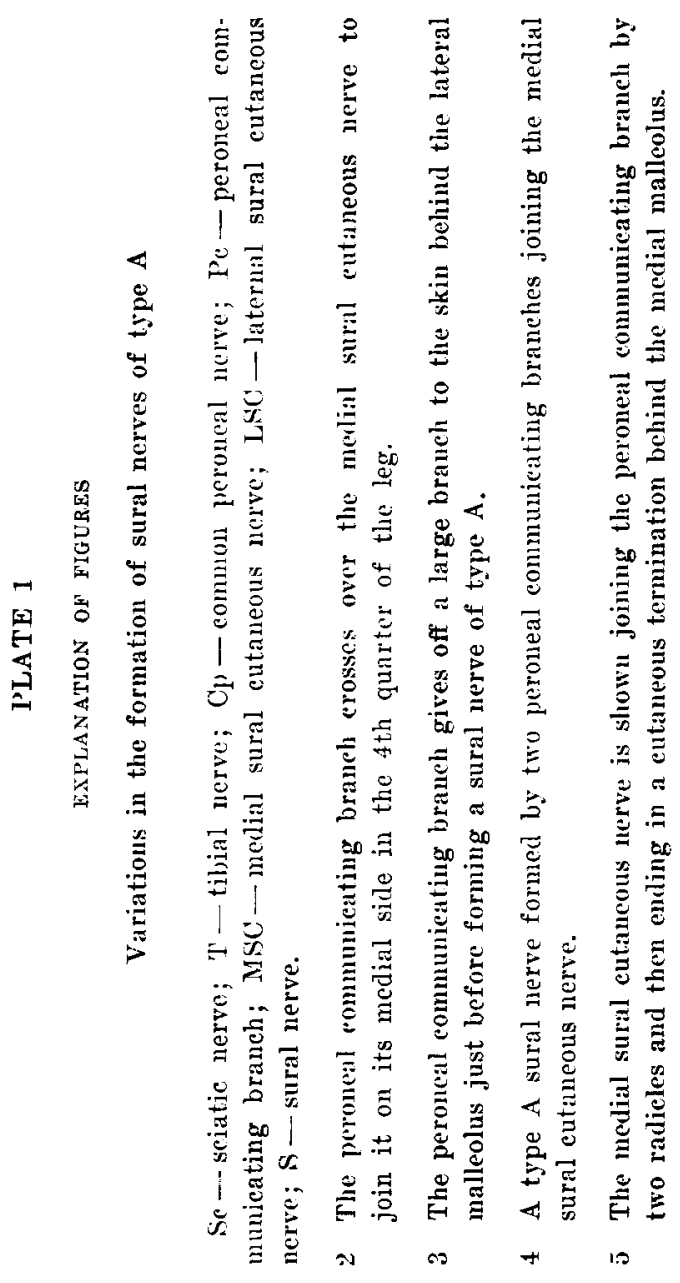


章
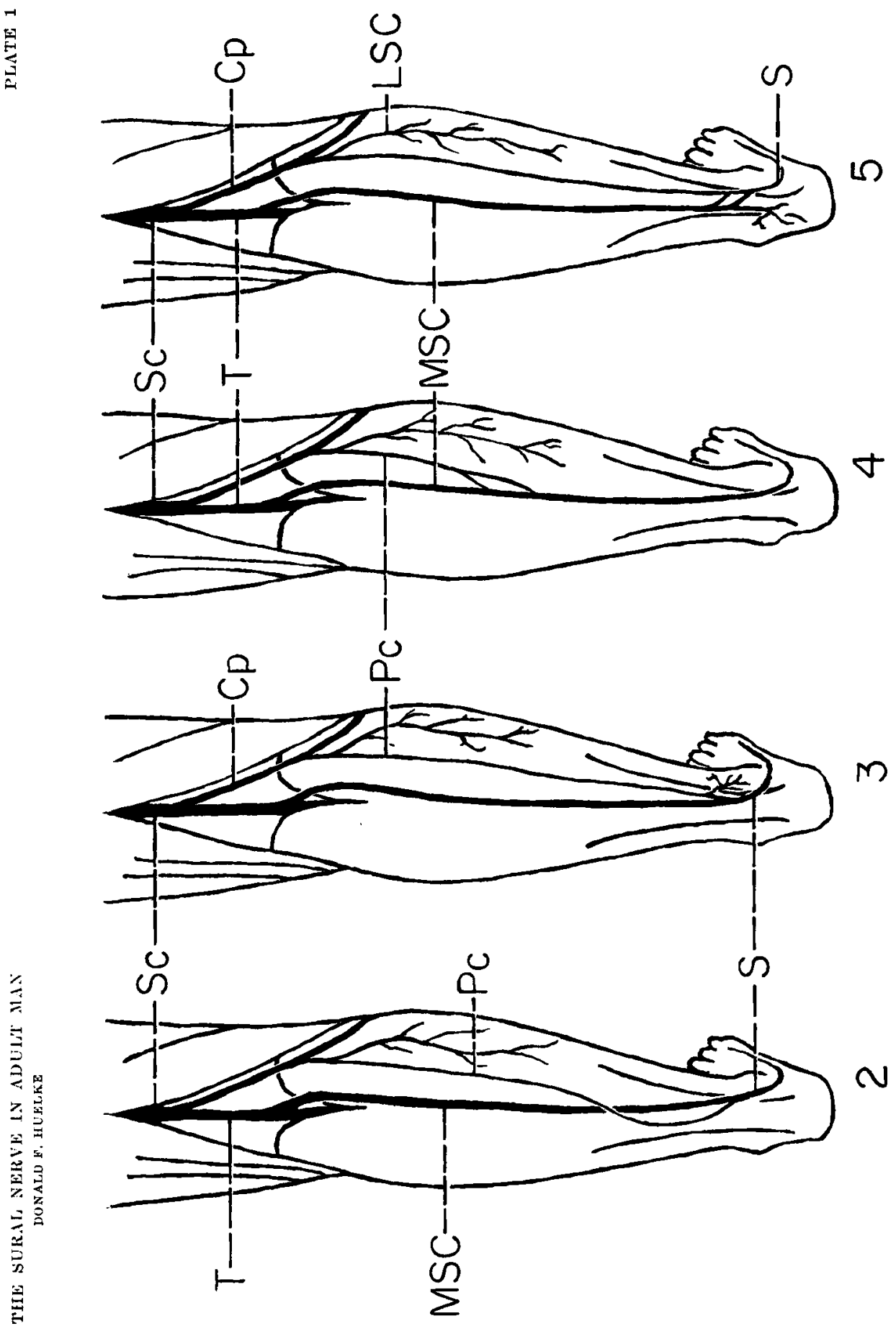